\title{
Component Analysis of Pressure Drop and Ventilation Variability*
}

\author{
by Dale E. Matbis
}

Research Laboratories, Eastman Chemicals Division, Eastman Kodak Company,

Kingsport, Tennessee, U.S.A.

\section{SUMMARY}

Mathematical models were derived that describe the variability of ventilation and pressure drop as functions of cigarette design specifications and the variabilities of cigarette components. These models and the graphical isovariation contour representation have several important potential applications for quality control and improvement. For example, the models can be used in cigarette performance studies to determine the relative contributions of each source of variability and to identify the largest source of variability. The models can be used in quality improvement to target programs for maximum effectiveness and to set realistic goals for quality improvement. The quantitative variability values that the models produce can also be used to establish acceptance limits for the variabilities of the cigarette components which control ventilation and pressure drop variability within specified limits. These applications and the insight into the causes of variability that these models can provide should make them a valuable tool for improving the uniformity of cigarette performance.

\section{ZUSAMMENFASSUNG}

Zur Bestimmung von Ventilations- und Zugwiderstandsschwankungen in Abhängigkeit vom Zigarettendesign und den Zigarettenbestandteilen wurden mathematische Modellgleichungen entwickelt. In der Qualitåtskontrolle und der Qualitätsverbesserung gibt es für solche Gleichungen wie auch für die graphische Darstellung im Isoliniendiagramm mancherlei wichtige Anwendungsmöglichkeiten. Zum Beispiel kann bei der Untersuchung der Leistungscharakteristik einer Zigarette mit Hilfe der Gleichungen bestimmt werden, in

\footnotetext{
* Presented at the 35th Tobacco Cbemists ${ }^{2}$ Research Conference, Winstor-Salem, N. C., in 1981.

Received: 10th March 1983 - accepted: 5th December 1983.
}

welchem Maße einzelne Eigenschaften die Schwankungen anteilig verursachen und von welchem Faktor der stärkste Einfluß ausgeht. Im Hinblick auf die Verbesserung der Qualitāt können mit den Gleichungen auch Programme zur Entwicklung höchster Gütekriterien erstellt und realistische Qualitātsziele formuliert werden. Es können mit Hilfe der Gleichungen auch Toleranzen festgelegt werden für die Größen, die Ventilationsgrad und Zugwiderstand bestimmen. Hinsichtlich der Erzielung einer, größeren Einheitlichkeit in der Leistungscharakteristik von Zigaretten könnten Berechnungen dieser Art und der durch die Gleichungen ermöglichte Einblick in die Schwankungsursachen wertvolle Hilfsmittel sein.

\section{RESUME}

Des modèles mathématiques ont été développés pour la détermination des variations de ventilation et de résistance au tirage en fonction de la structure des cigarettes et de leurs constituants. Il existe de nombreuses possibilités d'utilisation de ces équations ou de leurs représentations graphiques sous forme d'abaque, dans le cadre du contrôle ou de l'amélioration de la qualité. Les modèles peuvent être utilisés par exemple lors des études de performances d'une cigarette, pour déterminer la part relative prise par chacune de ses caractéristiques dans les variations et pour déceler ainsi celui des facteurs agissant le plus fortement sur les variations. Les équations modèles peuvent être de même utilisées avec une optique d'amélioration de la qualité en combinant des critères très pointus avec des objectifs réalistes. A l'aide de ces équations, on peut également déterminer les tolérances admissibles pour les composants de la cigarette responsables des variations de ventilation et de résistance au tirage. $\mathrm{La}$ compréhension que ces équations modèles donnent des causes de variations, devraient faire de celles-ci un remarquable instrument permettant de mieux harmoniser les caractéristiques et performances des cigarettes. 


\section{INTRODUCTION}

The rapidly increasing use of ventilation for reducing cigarette smoke deliveries has significantly complicated the design and control of cigarette performance. Many of the problems associated with the design of ventilated cigarettes have been overcome by the development of mathematical relationships that describe the performance of the cigarette as a function of its design specifications. However, this has not been so for the control of variability in these systems. The study of the variability of ventilated cigarettes is extremely complicated, and, as a result, this topic is poorly understood.

Two important properties of ventilated cigarettes that must be controlled are ventilation and cigarette pressure drop. This study presents and examines equations that describe ventilation and pressure drop variabilities for ventilated filter cigarettes as functions of the variation in cigarette components. The term components here refers to the basic building blocks of the cigarette - specifically, the filter, tobacco column, and vent system. The vent system consists of plug wrap and tipping paper, but vent performance depends strongly on the details of their combination. For this reason, the effects of these individual components were evaluated collectively in this study.

\section{THEORETICAL}

A three-step procedure was developed to derive equations for the variability of ventilation and pressure drop. Step 1 is to specify the independent variables that have a significant effect on ventilation and pressure drop. Step 2 is to determine the mathematical relationships between the variables identified in step 1 and ventilation and pressure drop. These two steps result in the equations shown in Appendix 4 which describe ventilation and pressure drop as functions of the cigarette design specifications. These equations were derived by modeling the cigarette components with electrical resistors and solving for the pressure drop in terms of the total resistance and for the ventilation as a ratio of currents.

The third and final step is to derive relationships between ventilation and pressure drop variabilities and the variabilities of the significant parameters by using the relationships shown in Appendix 2 (1). These equations permit the standard deviation of a dependent variable to be related to the standard deviations of the independent variables if the relationship of the dependent to the independent variables is known. For example, if the dependent quantity equals the independent variable, $x$, times a constant, then its standard deviation is equal to the product of the constant and the standard deviation of $x$. All the equations in Appendix 2 can be used in this same manner to determine variability relationships for algebraic combinations of two independent variables. Operations involving more than two variables are treated by repeated application of the appropriate equations.

The equation that describes the standard deviation of the cigarette pressure drop is derived in Appendix 5 by applying the variability relationships from Appendices 2 and 3 to the pressure drop equation obtained in Appendix 4. The final result of this derivation is shown here (see Appendix 1 on p. 174 for nomenclature):

$$
s_{v c}=\sqrt{D^{4} s_{v}^{2}+(1-D)^{4}\left(s_{t}^{2}+\frac{L_{u}}{L_{f}} s_{f}^{2}\right)+\frac{L_{d}}{L_{f}} s_{f}^{2}} .
$$

This equation relates the standard deviation of the ventilated cigarette pressure drop to the standard deviations of the vent system, tobacco column, and filter pressure drops. Examination of the equation reveals that pressure drop variability is generated by. three sources: the vent system, the upstream segment of the cigarette, and the downstream segment of the filter. Because all the flow through the cigarette passes through the downstream segment of the filter, this source of variability is weighted by a factor of one. Only a portion of the total flow passes through either the upstream portion of the cigarette or the vents, however; so these contributors are weighted by a factor related to the fraction of the total flow passing through each. These flow fractions are described mathematically as functions of the level of ventilation. Thus, this equation can be used to calculate theoretical values of cigarette pressure drop variability given the ventilation, vent position, absolute values, and standard deviations of the cigarette components' pressure drops.

Application of the equations for estimating variability given in Appendices 2 and 3 to the relationship describing ventilation level from Appendix 4 and appropriate algebraic manipulation shown in Appendix 6, result in the equation for ventilation variability shown here:

$$
C_{D}=(1-D) \sqrt{\frac{\left(\frac{L_{u}}{L_{f}} P_{f}^{2} C_{f}^{2}+P_{t}^{2} C_{t}^{2}\right)}{\left(\frac{L_{u}}{L_{f}} P_{f}+P_{t}\right)^{2}}+C_{v}^{2}} .
$$

Relative variabilities, also referred to as coefficients of variation, are the final result of this model rather than standard deviations. This permits the direct comparison of the effects of different sources of variability, although the absolute magnitudes of the average values differ significantly. Thus this equation describes the relative variability of ventilation level as a function of the relative variabilities of the filter, tobacco column, and vent system pressure drops. Two observations based on this equation can be made regarding ventilation variability. First, the relative variability of ventilation is proportional to the quantity one minus the ventilation level. The relative uniformity of ventilation should, therefore, improve as ventilation level increases even if no 
improvements are made in the uniformity of the cigarette components. Second, the contribution of each cigarette component to the ventilation variability is weighted according to the design of the cigarette, but the relative variability of the vent system always has the largest weighting. The relative contributions of the filter and the tobacco column are weighted approximately according to the fraction of the upstream pressure drop generated by each. This equation can, therefore, be used to calculate a theoretical value for the relative variability of ventilation given the design specifications of the cigarette and the relative variabilities of the filter, tobacco column, and vent system pressure drops.

\section{EXPERIMENTAL}

A four-part experiment was designed to test the validity of these mathematical models. First, 50 cigarettes were sampled from each of 12 different commercially available cigarette brands spanning a wide range of ventilation levels. Second, averages, standard deviations, and relative variabilities of the cigarette, filter, and tobacco column pressure drops, and the filter tip ventilation level were determined for each brand by measuring these quantities for each cigarette. All pressure drop and ventilation measurements were made at an exit flow rate of $1050 \mathrm{~cm}^{3} / \mathrm{min}$ with a vacuum instrument designed and constructed in this laboratory (2). Third, the average vent pressure drop and its relative variability were estimated for each brand. This was accomplished by cutting the filters from each cigarette, sealing the upstream end of each filter tip, and measuring the pressure drop across the vents at an exit flow of $1050 \mathrm{~cm}^{3} / \mathrm{min}$. However, because this technique does not completely isolate the vent system, the measured averages and standard deviations had to be corrected for the series contribution of the downstream filter segment by subtracting its pressure drop and variability. Because the vent pressure drop is not a linear function

Table 1. Specifications of commercial cigarettes.

\begin{tabular}{c|c|c|c|c}
\hline \multirow{2}{*}{$\begin{array}{c}\text { Ventilation } \\
(\%)\end{array}$} & $\begin{array}{c}\text { Vent position } \\
\text { ratio }\end{array}$ & \multicolumn{2}{|c}{ Pressure drops } & \multicolumn{2}{c}{ (mmw.g.) } \\
\cline { 3 - 5 } & & Filter & Tobacco & Cigarette \\
\hline 9.1 & 0.48 & 71.1 & 54.7 & 119.5 \\
15.7 & 0.54 & 71.9 & 76.7 & 131.7 \\
24.8 & 0.46 & 89.4 & 47.3 & 117.0 \\
26.3 & 0.46 & 120.0 & 41.8 & 138.0 \\
33.9 & 0.46 & 94.9 & 58.8 & 121.1 \\
35.3 & 0.63 & 102.2 & 49.5 & 112.8 \\
55.2 & 0.60 & 153.4 & 46.2 & 125.0 \\
60.5 & 0.46 & 106.8 & 39.4 & 105.1 \\
66.5 & 0.50 & 114.1 & 99.7 & 109.5 \\
69.2 & 0.40 & 105.2 & 43.1 & 99.0 \\
75.1 & 0.44 & 148.1 & 54.4 & 104.4 \\
88.2 & 0.48 & 232.7 & 85.1 & 146.3 \\
\hline
\end{tabular}

of the flow rate through the vents, the average values obtained by this measurement technique cannot be used to estimate cigarette pressure drops or ventilation levels. These measurements do provide an accurate estimate of the relative variability of the vent pressure drop because the effects of flow rate are largely removed by dividing the standard deviation by the average. Finally, the variabilities of cigarette pressure drop and ventilation were predicted by using the mathematical models and the quantities measured in the experiment. These results were compared with the measured values.

\section{RESULTS AND DISCUSSION}

\section{PART I: Evaluation of the Variability Equations}

The results of the experiment are shown in Tables 1 and 2. Table 1 summarizes the specifications of the commercial cigarettes studied. The 12 brands studied covered the wide range of average ventilation from $9.1 \%$ to $88.2 \%$. Although there are considerable differences between brands, the characteristics of a typical ventilated cigarette can be approximated by taking the average for all 12 brands of each specification after discarding unusually high or low values. The results indicate that the average cigarette exhibits a filter pressure drop of about $100 \mathrm{~mm}$, a tobacco column pressure drop of about $50 \mathrm{~mm}$, a cigarette pressure drop of about $120 \mathrm{~mm}$, and a vent location at the midpoint of the filter.

Table 2 lists the percent relative variability of the filter, tobacco column, vent system pressure drops, the measured and predicted ventilation variabilities, and the measured and predicted standard deviation of cigarette pressure drop. The agreement between the measured and predicted variabilities is good for both models, especially considering that the predicted values are calculated from eight measured quantities, three of which are variabilities that cannot be measured as accurately as pressure drops and dimensions. The last row of the table lists the average values for each column and demonstrates that there is no significant bias between the predicted and measured variabilities. The other average values indicate the relative magnitude of the variability of the cigarette components. For the brands sampled in this study, the filter is the least variable component, followed by the tobacco column and the vent system. Because the vent system is the most variable cigarette component, as well as the most heavily weighted source of ventilation variability, vent system variability is the major source of ventilation variability.

Figures 1 and 2 are plots of measured versus predicted values for the variability of pressure drop and ventilation. The best fit line through the data is also shown to demonstrate the validity of the equations. Figure 1 shows that the measured pressure drop variability $\left(s_{\mathrm{vc}}\right)$ equals $-0.15+1.08$ times the predicted standard devia- 
Figure 1.

Measured vs. predicted pressure drop varlability.

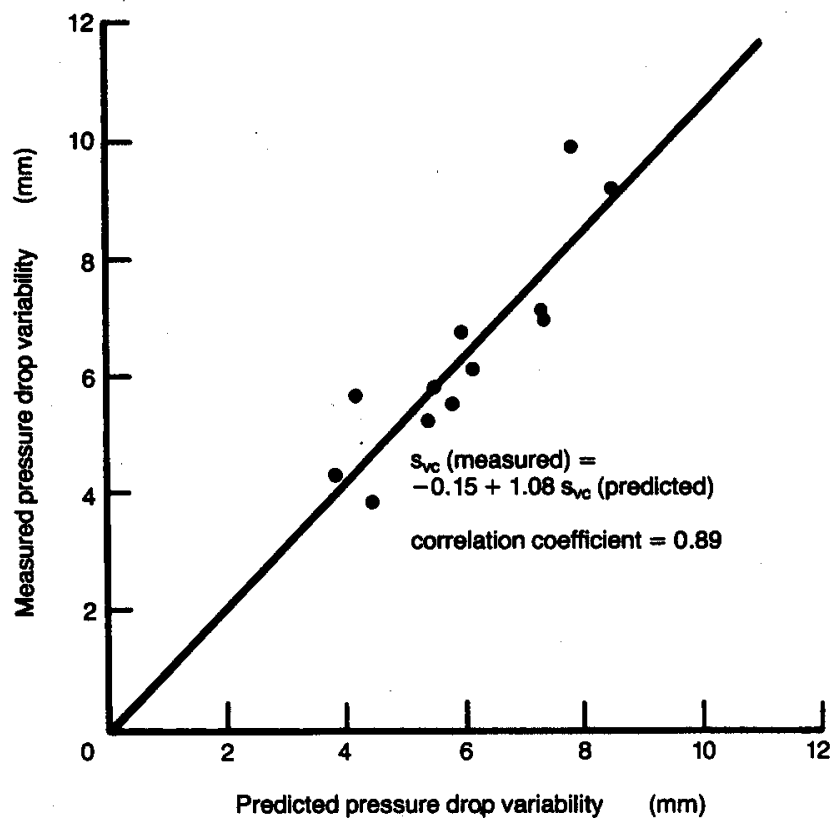

Figure 2.

Measured vs. predicted ventllation varlabllity.

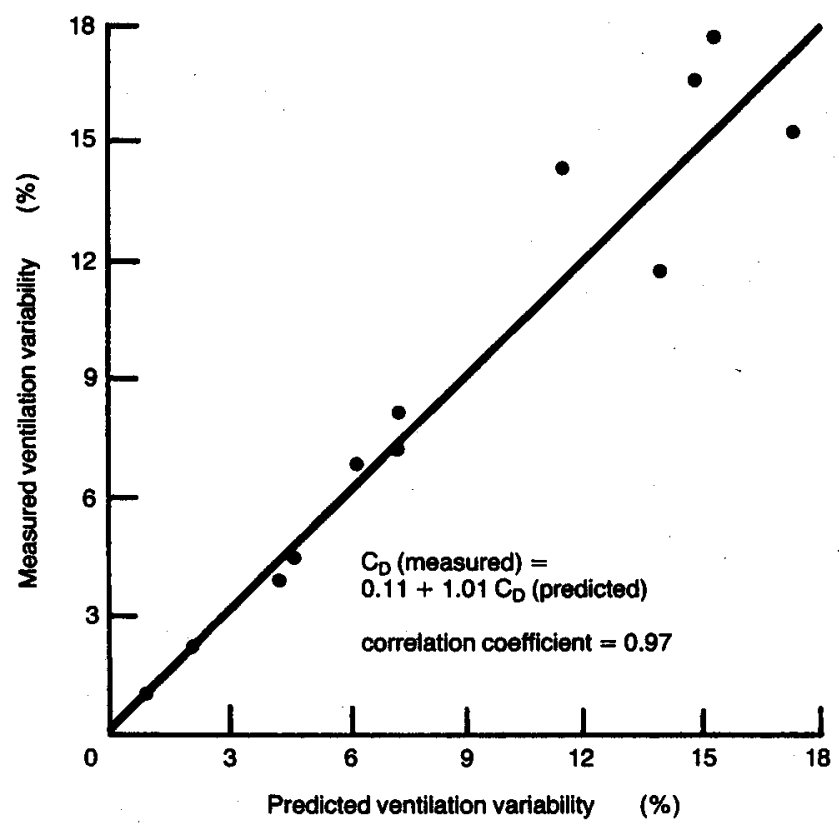

Table 2. Results of dilution variability experiment.

\begin{tabular}{|c|c|c|c|c|c|c|c|}
\hline \multirow{2}{*}{$\begin{array}{c}\text { Ventilation } \\
(\%)\end{array}$} & \multicolumn{3}{|c|}{ Relative variability } & \multicolumn{2}{|l|}{$(\%)$} & \multicolumn{2}{|c|}{ Standard deviation } \\
\hline & $\begin{array}{l}\text { Filter } \\
\text { pressure } \\
\text { drop }\end{array}$ & $\begin{array}{l}\text { Tobacco } \\
\text { pressure } \\
\text { drop }\end{array}$ & $\begin{array}{l}\text { Vent } \\
\text { pressure } \\
\text { drop }\end{array}$ & $\begin{array}{l}\text { Measured } \\
\text { ventilation. }\end{array}$ & $\begin{array}{l}\text { Predicted } \\
\text { ventilation }\end{array}$ & $\begin{array}{l}\text { Measured } \\
\text { pressure } \\
\text { drop }\end{array}$ & $\begin{array}{c}\text { Predicted } \\
\text { pressure } \\
\text { drop }\end{array}$ \\
\hline 9.1 & 5.67 & 8.39 & 15.41 & 17.4 & 15.3 & 5.3 & 5.9 \\
\hline 15.7 & 6.48 & 10.02 & 19.41 & 15.2 & 17.4 & 7.0 & 7.4 \\
\hline 24.8 & 6.82 & 6.69 & 18.79 & 16.5 & 14.8 & 6.2 & 6.2 \\
\hline 26.3 & 7.87 & 6.39 & 17.55 & 11.7 & 14.0 & 9.2 & 8.6 \\
\hline 33.9 & 3.78 & 11.83 & 15.79 & 14.1 & 11.5 & 5.8 & 5.5 \\
\hline 35.3 & 4.33 & 9.31 & 10.47 & 7.3 & 7.5 & 3.8 & 4.5 \\
\hline 55.2 & 3.00 & 10.82 & 8.19 & 3.7 & 4.2 & 5.6 & 4.2 \\
\hline 60.5 & 5.85 & 2.38 & 18.13 & 7.9 & 7.4 & 6.8 & 6.0 \\
\hline 66.5 & 6.62 & 16.46 & 15.46 & 6.8 & 6.4 & 9.9 & 7.8 \\
\hline 69.2 & 6.63 & 12.54 & 12.20 & 4.3 & 4.5 & 5.6 & 5.9 \\
\hline 75.1 & 3.25 & 8.09 & 6.60 & 2.0 & 2.0 & 4.3 & 3.9 \\
\hline 88.2 & 4.34 & 9.31 & - & 0.7 & 0.7 & 7.1 & 7.4 \\
\hline Average & 5.39 & 9.35 & 14.36 & 9.0 & 8.8 & 6.4 & 6.1 \\
\hline
\end{tabular}


tion with a correlation coefficient of 0.89 . The lack of fit for the points versus the best fit line appears to be randomly distributed. The plot for ventilation variability is shown in Figure 2 and linear regression demonstrates that the measured variability $\left(C_{D}\right)$ equals 0.11 plus 1.01 times the predicted ventilation variability with a correlation coefficient of 0.97 . The deviation of the data points from this least squares line increases as the absolute value of the variability increases. In fact, the model is virtually exact for predicting ventilation variabilities up to values of about $10 \%$.

\section{PART II: Variability Behavior of Ventilated Cigarettes}

The dependence of pressure drop and ventilation variabilities on ventilation level predicted by the mathematical models is shown graphically in Figure 3 for the average ventilated cigarette described earlier. It is assumed that ventilation level is varied by changing only the vent system pressure drop, but that the relative variability of the vent system pressure drop $\left(C_{v}\right)$ always remains constant at $15 \%$. The graph demonstrates that the relative variability of ventilation $\left(C_{D}\right)$ decreases with increasing ventilation level, as was predicted from the variability equation. It also shows that the standard deviation $\left(s_{\mathrm{D}}\right)$ of ventilation reaches a maximum at $50 \%$ ventilation and decreases to zero as ventilation approaches 0 or $100 \%$. Both the standard deviation and the percent relative variability of pressure drop are much more independent of ventilation level. Pressure drop standard deviation $\left(s_{\mathrm{rc}}\right)$ decreases slightly as ventilation increases, whereas the relative variability $\left(C_{v c}\right)$ increases. An important result of this behavior is that

Figure 3.

Effects of ventllation on variability.

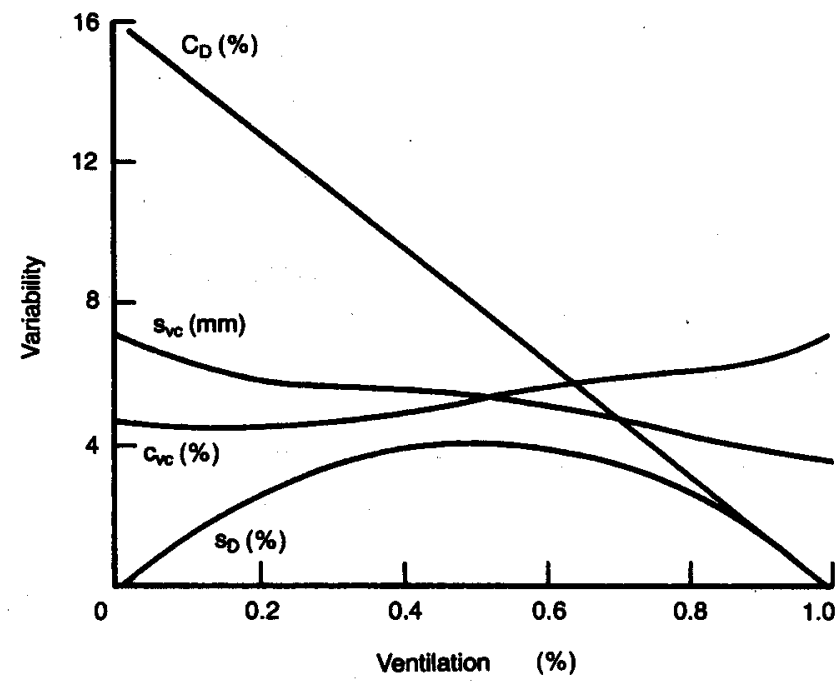

Clgarette specifications:

$$
\begin{array}{lrl}
P_{1}=100 \pm 5 \mathrm{~mm} w . g . & L_{v} / L_{1}=0.5 \\
P_{1}=50 \pm 5 \mathrm{~mm} \text { w.g. } & C_{v}=0.15
\end{array}
$$

Figure 4.

lsovarlation contours of ventllation and pressure drop.

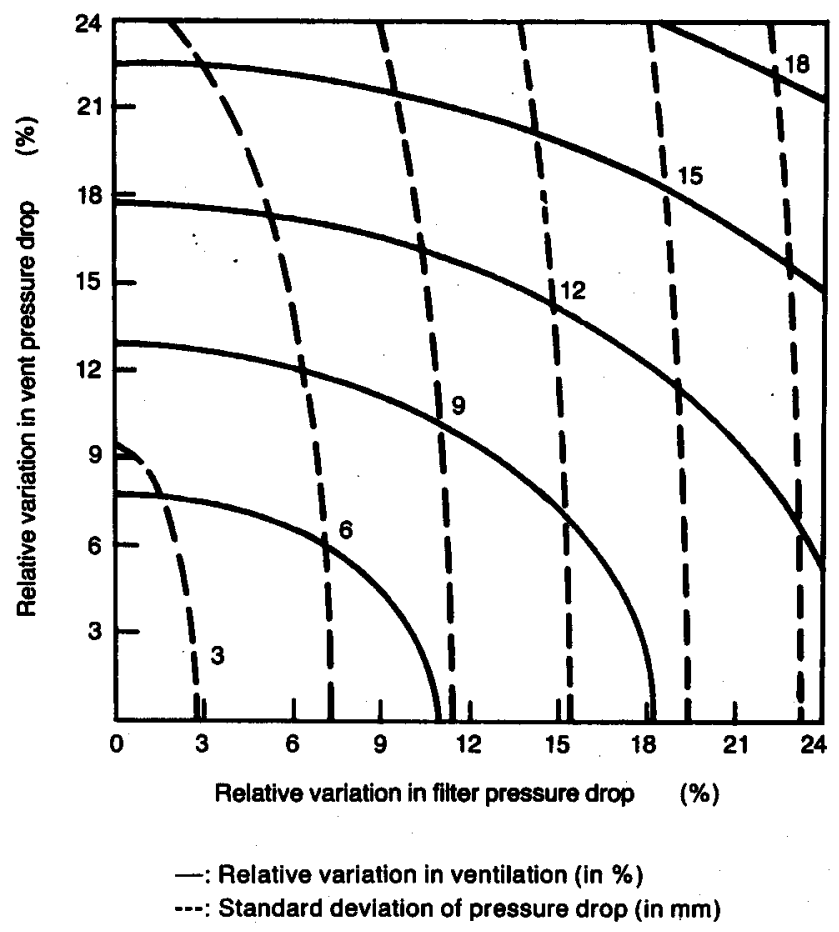

measurement of pressure drop variability is clearly not a good indication of ventilation variability and should not be used as the only means of quality control.

The models presented can be used to examine variability in cigarette performance, but the manipulation of these equations is awkward compared to a graphical representation of the information they contain. Although graphs are limited to displaying the effects of only two sources of variability, it is possible to characterize the ventilation and pressure drop variability behavior for a specific cigarette design by using the isovariation contour plot shown in Figure 4. The effects of vent system and filter pressure drop variability are depicted by this plot, while the relative variability of tobacco column pressure drop is held constant at its average value of $10 \%$. The relative variabilities of these parameters, in percent, are incremented along the major axes, and lines of constant relative ventilation variability and pressure drop standard deviation are drawn on the graph. This format permits the variability of ventilation and pressure drop to be examined simultaneously as functions of the relative variability of the filter and vent system pressure drops. The graph reveals the relative importance of the vent system and the filter as sources of variability and to what degree these components must be controlled to maintain cigarette variability within specified limits. For example, the isovariation contour plot for the average cigarette ventilated at $35 \%$, which is shown in Figure 4, demonstrates that the vent system variability is the major source of ventilation variation. Pressure drop variability is more strongly influenced by the filter because at the low lev- 
el of ventilation used in this example, the filter is the main source of cigarette pressure drop.

\section{REFERENCES}

1. Goodman, L. A.: On the exact variance of products; Journal of the American Statistical Association 55 (292), (1960) 708-713.

2. Weatherly, C. H., J. E. Kiefer: Instrument for simultaneous measurement of pressure drop and filter

Appendix 1.

Legend of symbols.

Part 1: Major symbols

$P_{I} \quad$ Pressure drop of component I

$s_{\mathrm{I}}$ Standard deviation of $\mathrm{I}$

$\mathrm{C}_{\mathrm{I}}$ Relative variation of $\mathrm{I}\left(\mathrm{S}_{\mathrm{I}} / \mathrm{P}_{\mathrm{I}}\right)$

$L_{I} \quad$ Length of I

D Fractional ventilation

\section{Part 2: Subscripts}

$f \quad$ Filter

t Tobacco column

V Vent system

D Fractional ventilation

u Filter upstream of vents

d Filter downstream of vents

c Non-vented cigarette

vc Vented cigarette ventilation; Eastman Technical Information for Customer Dissemination, Filter Technology Report No. 64.

Author's address:

Research Laboratories, Eastman Chemicals Division, Eastman Kodak Company, Kingsport, Tennessee, 37662, U.S.A.
Appendix 2.

Equations for estimating variability.

Operation

Equation

Scalar addition

$s[k+x]-s[x]$

Variable addition

$s[x+y]=\sqrt{s^{2}[x]+s^{2}[y]}$

Scalar multiplication

$s[k \cdot x]=k \cdot s[x]$

Variable multiplication

$s[x \cdot y]=\sqrt{x^{2} \cdot s^{2}[y]+y^{2} \cdot s^{2}[x]}$

Inverse

$s[1 / x]=s[x] / x^{2}$

Variable division

Appendlx 3.

Relation of pressure drop variation to length for fliters.

Although the variation in filter pressure drop can readily be measured, many of the equations derived in this study use the pressure drop variability of a short length or segment of the filter, which generally cannot be measured. Determining the relationship of filter pressure drop variation to length makes it possible to calculate the variability of any length of filter segment from the pressure drop variability of the filter. 
Filter pressure drop can be treated as the series sum of a large number (n) of very small pressure drop elements with a minute average pressure drop $\left(P_{f} / n\right)$ and a standard deviation $\left(s_{\theta}\right)$. The pressure drop of the fllter is equal to the sum of all the pressure drop elements or mathematically,

$$
P_{f}=\sum_{i=1}^{n} P_{f} / n=n P_{f} / n=P_{f}
$$

But the variance of the filter pressure drop equals the sum of the squares of the standard deviations of all of the pressure drop elements so that

$$
s_{f}^{2}-\sum_{i=1}^{n} s_{e_{1}}^{2}=n s_{e}^{2}
$$

Because the length of the individual pressure drop elements is constant, the number of elements is proportional to the length of the filter segment. Equation 2 demonstrates that pressure drop variance $\left(s_{f}^{2}\right.$ is proportional to the number of elements and, therefore, must also be proportional to filter length. Consequently, the standard deviation of filter pressure drop must vary as the square root of filter length:

$$
s_{1} \propto \sqrt{L_{1}}
$$

Equation 3 can be tested experimentally by measuring the pressure drop average and standard deviation for a sample of filter rods and then very accurately cutting the rods in half and repeating the measurement. Data for such an experiment using three filter tow specifications and a filter rod circumference of $24.8 \mathrm{~mm}$ are shown below:

Pressure drop average and standard deviation as a function of filter rod length

\begin{tabular}{c|ccc}
\hline \multirow{3}{*}{$\begin{array}{c}\text { Length } \\
(\mathrm{mm})\end{array}$} & \multicolumn{4}{|c}{ Tow item } \\
& $1.8 / 42$ & $3.3 / 42$ & $5.0 / 41$ \\
\cline { 2 - 4 } & $\mathrm{P}_{\mathrm{f}}$ & $\mathrm{P}_{\mathrm{f}}$ & $\mathrm{P}_{\mathrm{f}}$ \\
& $\pm \mathrm{s}_{\mathrm{f}}$ & $\pm \mathrm{s}_{\mathrm{f}}$ & $\pm \mathrm{s}_{\mathrm{f}}$ \\
\hline 120 & 524.1 & 342.0 & 236.3 \\
& 13.57 & 8.41 & 7.18 \\
60 & 277.6 & 183.5 & 121.1 \\
& 9.15 & 5.35 & 4.79 \\
30 & & & 59.7 \\
& 141.7 & 93.0 & 2.93 \\
& - & 3.60 & \\
15 & & & 29.4 \\
& 69.9 & 45.8 & 1.73 \\
\hline
\end{tabular}

Linear regression analysis of these data verifies the dependence of $s_{1}$ on the square root of filter fength, which was predicted by equation 3. The analysis for the $1.8 / 42$ tow item gives a correlation coefficient of 0.9995 for the square root relationship. Correlation coefficients of 0.9989 and 0.9998 were obtained for the $3.3 / 42$ and 5.0/41 items.
Appendlx 4.

Derlvation of pressure drop and ventilation equations.

The flow - pressure drop behavior of a vented filter cigarette is modeled by the following resistor network:

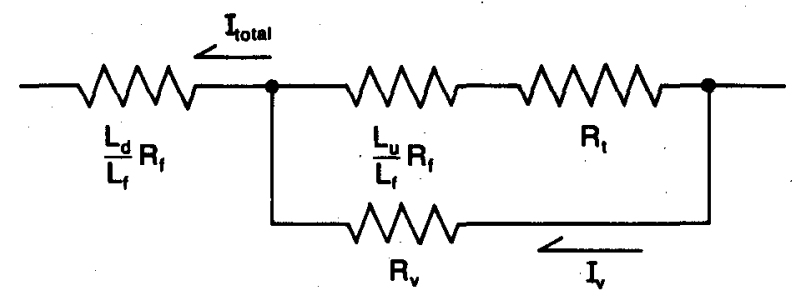

where $R$ is the electrical resistance in ohms, $I$ is the current in amperes, and $I_{\text {total }}$ is the sum of the current through $R_{v}$ and $R_{t}$.

\section{Part 1: Pressure drop}

The voltage drop across this equivalent circuit is analogous to the cigarette pressure drop and is described as follows:

$$
\Delta V=I_{\text {total }} \cdot\left[\left(\frac{1}{R_{v}}+\frac{1}{R_{t}+\frac{L_{u}}{L_{f}} R_{f}}\right)^{-1}+\frac{L_{d}}{L_{f}} R_{f}\right] .
$$

Because standard flow conditions are always used for pressure drop measurements, pressure drop can be substituted for resistance as follows:

$$
P_{v c}=\left(\frac{1}{P_{v}}+\frac{1}{P_{t}+\frac{L_{u}}{L_{f}} P_{t}}\right)^{-1}+\frac{L_{d}}{L_{f}} P_{f} .
$$

\section{Part 2: Ventilation}

The ratio of the current flowing through $R_{v}, I_{v}$, to the total current, $I_{\text {total }}$, is equivalent to the fraction of ventllation. Ohm's law states that $I$ is proportional to $1 / R$, so the ventilation equals

$$
D=\frac{I_{v}}{I_{\text {total }}}=\frac{R_{\text {total }}}{R_{v}}
$$

The total resistance upstream of the vents, $R_{\text {total, }}$ can be determined by solving the parallel and series combinations of $R_{f}, R_{t}$ and $R_{v}$ to give

$$
D=\frac{1}{R_{v}} \cdot \frac{R_{v}\left(\frac{L_{u}}{L_{f}} R_{t}+R_{t}\right)}{\frac{L_{u}}{L_{t}} R_{f}+R_{t}+R_{v}} .
$$

Equation 4 simplifies to give

$$
D=\frac{\frac{L_{u}}{L_{f}} R_{f}+R_{t}}{\frac{L_{u}}{L_{t}} R_{f}+R_{t}+R_{v}}
$$


Ohm's law also states that resistance is directly proportional to voltage so the analogous quantity, pressure drop, can be substituted into equation 3 . This substitution is valid only if $P_{t}, P_{t}$ and $P_{v}$ have all been determined at the same flow rate. Equation 6 is the final result:

$$
D=\frac{\frac{L_{u}}{L_{1}} P_{f}+P_{t}}{\frac{L_{u}}{L_{f}} P_{f}+P_{t}+P_{v}}
$$

Appendix 5.

Derivation of pressure drop variation equations.

In Appendix 4, the pressure drop of a vented cigarette was determined to be described by the following equation:

$$
P_{v c}=\left(\frac{1}{P_{v}}+\frac{1}{P_{1}+\frac{L_{u}}{L_{t}} P_{f}}\right)^{-1}+\frac{L_{d}}{L_{f}} P_{f}
$$

Application of the variability rule for sums gives:

$$
s_{v c}^{2}=s^{2}\left[\left(\frac{1}{P_{v}}+\frac{1}{P_{t}+\frac{L_{u}}{L_{t}} P_{t}}\right)^{-1}\right]+s^{2}\left[\frac{L_{d}}{L_{t}} P_{f}\right] .
$$

Application of the variability rule for inverses and the result that

$s^{2}\left[\frac{L_{d}}{L_{1}} P_{1}\right]=\frac{L_{d}}{L_{1}} s_{1}^{2}$

from Appendix 3 gives:

$$
s_{v c}^{2}=\frac{s^{2}\left[\frac{1}{P_{v}}+\frac{1}{P_{t}+\frac{L_{u}}{L_{t}} P_{f}}\right]}{\left(\frac{1}{P_{v}}+\frac{1}{P_{t}+\frac{L_{u}}{L_{f}} P_{t}}\right)^{4}}+\frac{L_{d}}{L_{f}} s_{f}^{2}
$$

Algebraic manipulation and application of the sum rule for variability gives:

$$
s_{v c}^{2}=\frac{s^{2}\left[\frac{1}{P_{v}}\right]+s^{2}\left[\frac{1}{\left(P_{t}+\frac{L_{u}}{L_{t}} P_{t}\right)}\right]}{\left(\frac{P_{v}+P_{t}+\frac{L_{u}}{L_{t}} P_{t}}{P_{v}\left(P_{t}+\frac{L_{u}}{L_{t}} P_{t}\right)}\right)^{4}}+\frac{L_{d}}{L_{t}} s_{t}^{2}
$$

Application of the variability rule for inverses and substitution of equation 6 from Appendix 4 gives:

$s_{v c}^{2}=P_{v}^{4} D^{4}\left(s^{2}\left[P_{v}\right] / P_{v}^{4}+s^{2}\left[P_{t}+\frac{L_{u}}{L_{f}} P_{t}\right] /\left(P_{t}+\frac{L_{u}}{L_{t}} P_{t}\right)^{4}\right)+\frac{L_{d}}{L_{f}} s_{f}^{2} \cdot$

Solving for the variability of sums, substituting the following equations and simplifying gives equation 6 :

$$
\begin{aligned}
s^{2}\left[P_{v}\right]=s_{v}^{2} & \text { by definition } \\
s^{2}\left[P_{t}\right]=s_{t}^{2} & \text { by definition } \\
s^{2}\left[\frac{L_{u}}{L_{i}} P_{t}\right]-\frac{L_{u}}{L_{i}} s_{f}^{2} & \text { from Appendix } 3
\end{aligned}
$$

$$
s_{v c}^{2}=D^{4} s_{v}^{2}+\frac{D^{4} P_{v}^{4}\left(s_{t}^{2}+\frac{L_{u}}{L_{f}} s_{f}^{2}\right)}{\left(P_{t}+\frac{L_{u}}{L_{f}} P_{t}\right)^{4}}+\frac{L_{d}}{L_{t}} s_{f}^{2} .
$$

Substituting equation 6 from Appendix 4 and taking the square root gives the final result:

$$
s_{v c}=\sqrt{D^{4} s_{v}^{2}+(1-D)^{4}\left(s_{i}^{2}+\frac{L_{u}}{L_{f}} s_{f}^{2}\right)+\frac{L_{d}}{L_{f}} s_{f}^{2}} .
$$

The pressure drop variability of a non-vented cigarette is obtained by setting $D$ equal to zero:

$$
s_{c}=\sqrt{s_{t}^{2}+\frac{L_{u}}{L_{f}} s_{f}^{2}+\frac{L_{d}}{L_{f}} s_{f}^{2}}=\sqrt{s_{t}^{2}+s_{f}^{2}}
$$

Appendix 6. Derivation of ventilation varlation equation.

\section{Part 1: Equation for standard deviation of ventilation}

The relationship between the fraction of ventilation and the cigarette component pressure drops was derived in Appendix 4 and is

$$
D=\frac{\frac{L_{u}}{L_{f}} P_{t}+P_{t}}{\frac{L_{u}}{L_{i}} P_{t}+P_{t}+P_{v}}
$$

However, the numerator and denominator of equation 1 are highly correlated so the variability of this quotient cannot be accurately estimated. This correlation does not exist in the 
simplified reciprocal of equation 1, so an expression for ventilation variability can be obtained by solving for the variability of one over the ventilation and applying the rule for estimating the variability of reciprocals shown in equation 2 to the result:

$$
s_{D}=D^{2} s\left[\frac{1}{D}\right]
$$

Substituting equation 1 for $D$ and simplifying gives:

$$
s_{D}=D^{2} s\left[1+P_{v} /\left(\frac{L_{u}}{L_{f}} P_{f}+P_{t}\right)\right]
$$

Since the variability of a constant is zero, equation 3 simplifies to:

$$
s_{D}=D^{2} s\left[P_{v} /\left(\frac{L_{u}}{L_{f}}+P_{f}+P_{t}\right)\right]
$$

Applying the quotient rule for estimating variability:

$$
s\left[\frac{x}{y}\right]=\sqrt{x^{2} s^{2}[y]+y^{2} s^{2}[x]} / y^{2}
$$

gives:

$$
s_{D}=\frac{D^{2} \sqrt{P_{v}^{2} s^{2}\left[\frac{L_{u}}{L_{f}} P_{f}+P_{t}\right]+\left(\frac{L_{u}}{L_{f}} P_{f}+P_{t}\right)^{2} s^{2}\left[P_{v}\right]}}{\left(\frac{L_{u}}{L_{i}} P_{t}+P_{t}\right)^{2}}
$$

Applying the variability rule for sums:

$$
s^{2}[x+y]=s^{2}[x]+s^{2}[y]
$$

to equation 5 gives:

$$
s_{D}=\frac{D^{2} \sqrt{P_{v}^{2}\left(s^{2}\left[\frac{L_{u}}{L_{1}} P_{t}\right]+s^{2} P_{t}\right)+\left(\frac{L_{u}}{L_{t}} P_{t}+P_{t}\right)^{2} s^{2}\left[P_{v}\right]}}{\left(\frac{L_{u}}{L_{t}} P_{t}+P_{t}\right)^{2}}
$$

Substituting equation 1 for $D$ and the following relationships and performing some algebraic manipulation give the final result shown in equation 7 :

$$
\begin{gathered}
s^{2}\left[\frac{L_{u}}{L_{t}} P_{1}\right]=\frac{L_{u}}{L_{t}} s_{1}^{2} \quad \text { from Appendix } 3 \\
s^{2}\left[P_{t}\right]-s_{t}^{2} \quad \text { by definition } \\
s^{2}\left[P_{v}\right]=s_{v}^{2} \quad \text { by definition } \\
s_{D}=\frac{\sqrt{P_{v}^{2}\left(\frac{L_{u}}{L_{1}} s_{t}^{2}+s_{t}^{2}\right)+s_{v}^{2}\left(P_{t}+\frac{L_{u}}{L_{1}} P_{t}\right)^{2}}}{\left(\frac{L_{u}}{L_{1}} P_{t}+P_{t}+P_{v}\right)^{2}} .
\end{gathered}
$$

\section{Part 2: Equation for the relative variation of ventilation}

An equation based on relative variabilities is derived by making the following substitutions into equation 7 :

$$
\begin{aligned}
& s_{f}=P_{f} C_{f}, \\
& s_{t}=P_{t} C_{t}, \\
& s_{v}=P_{v} C_{v} .
\end{aligned}
$$

The result of these substitutions is:

$$
s_{0}=\frac{\sqrt{P_{v}^{2} \frac{L_{u}}{L_{f}} P_{t}^{2} C_{t}^{2}+P_{v}^{2} P_{t}^{2} C_{t}^{2}+P_{v}^{2} C_{v}^{2}\left(P_{t}+\frac{L_{u}}{L_{t}} P_{t}\right)^{2}}}{\left(\frac{\left.L_{u} P_{t}+P_{t}+P_{v}\right)^{2}}{L_{t}}\right.}
$$

Factoring $P_{v}$ out of equation 8 yields:

$$
s_{D}=\frac{P_{v}}{\left(\frac{L_{u}}{L_{t}} P_{f}+P_{t}+P_{t}\right)} \times
$$

$$
\sqrt{\frac{\frac{L_{u}}{L_{t}} P_{t}^{2} C_{i}^{2}+P_{t}^{2} C_{t}^{2}+\left(P_{t}+\frac{L_{u}}{L_{t}} P_{t}\right)^{2} C_{v}^{2}}{\left(\frac{L_{u}}{L_{i}} P_{t}+P_{t}+P_{t}\right)^{2}}}
$$

Substitution of equation 1 and algebraic manipulation yield:

$$
S_{D}=(1-D) \sqrt{\frac{D^{2}\left(\frac{L_{u}}{L_{f}} P_{t}^{2} C_{f}^{2}+P_{t}^{2} C_{t}^{2}\right)}{\left(\frac{L_{u}}{L_{t}} P_{t}+P_{t}\right)^{2}}+D^{2} C_{v}^{2}}
$$

Factoring $D$ out of equation 10 gives the final result for $s_{D}$ :

$$
s_{D}=(1-D) D \sqrt{\frac{\left(\frac{L_{u}}{L_{f}} P_{t}^{2} C_{f}^{2}+P_{t}^{2} C_{t}^{2}\right)}{\left(\frac{\left.L_{u} P_{f}+P_{t}\right)^{2}}{L_{t}}+C_{v}^{2}\right.}}
$$

An equation for the relative variation of ventilation is obtained simply by substituting $s_{D}=D C_{D}$ into equation 11 and solving for $C_{0}$ to give equation 12 :

$$
\left.C_{D}=(1-D)\right] \sqrt{\frac{\left(\frac{L_{u}}{L_{t}} P_{t}^{2} C_{f}^{2}+P_{t}^{2} C_{t}^{2}\right)}{\left(\frac{L_{u}}{L_{1}} P_{t}+P_{t}\right)^{2}}+C_{v}^{2}}
$$

